\title{
ORIGINS AND BARRIERS: REFLECTIONS ON SUBRAHMANYAM
}

\author{
Simon Schaffer (University of Cambridge)
}

It has been said that if completely known and understood, an historical phenomenon is therefore dead. ${ }^{1}$ Yet how perverse, so it might seem, that the scholarly revelation of a powerful concept's complex history might therefore be taken as an argument that it should therefore be entirely abandoned. This is, of course, not Sanjay Subrahmanyam's conclusion about the notion of Asia. The choice he poses is not between one Asia or none, but between a singular and overarching universal and an unevenly connected plurality. However, further complementary questions might pose themselves. Under what conditions can this plurality and these connections become anything like objects of knowledge? And of whose knowledge? These are, perhaps, issues where historians of the sciences might contribute. It is a distressingly familiar theme amongst those historians that it has too often been supposed that a demonstration of the historical construction and variable functions of an object is to be understood somehow as a denial of that object's existence or value.

Debates on the definition of Asia have long foundered on this puzzle, not least because it seems evident, as Subrahmanyam points out, that the concept emerged from an outsiders' perspective, a means of defining a boundary beyond which lay difference, exoticism, the alien. The resonance with Edward Said's critique of orientalism's externality is very clear ${ }^{2}$. Geopolitics is both responsible for and affected by such definitions. 'What is Asia?' In early 1987, in the wake of the Sino-British Joint Declaration that determined Hong Kong's fate, its principal news magazine, the Far Eastern Economic Review, sought to answer this question. In his editorial, the veteran journalist Philip Bowring, eventually to be sacked by the Review's new owners, Dow Jones backed by Rupert Murdoch's News Corp, insisted that 'the word Asia was invented by Europeans and its concept has been propagated by European geographers, politicians and encyclopaedia writers. The concept did not exist among Asian civilisations'. 
Other contributors, tasked with surveying the notion of Asia at work in Malaysia and Korea, China and Japan, India and the Middle East, concurred. It was claimed that 'huge and amorphous' Asia stayed 'at the periphery of Indian consciousness'. This was a concept of imagination, its unity the result of Europeans' 'ludicrous logic'. To the expert journalists of 1987, the consequences seemed clear: new geopolitical divisions would emerge, 'predominantly based on religion (such as Marxism)', while growth in some Asian nations' global dominance would see the very notion of Asia wither away. ${ }^{3}$

Rather than consign the notion of Asia to oblivion, to damn the term solely as a catastrophic legacy of the absurd reason of European hegemony, it seems more to the point to offer the kinds of studious genealogy and historical analysis that are on offer in Subrahmanyam's lecture. The concept, he shows, evidently did exist in various forms in the cultural projects of many Asian societies and its provenance and scope cannot be entirely confined to an orientalist thesis of external imposition by racism and colonialism. Subtle geographies and politics are in play in its usages. It is of some significance, it might well be added, that this feature in information geography especially applies in the sciences. In 1987, Bowring astutely noted that many current publications, journals and institutions, all used the term 'Asian' in their title without extending their scope much further west than Thailand. ${ }^{4}$ Several science journals whose titles evoke the grand scope of a singular Asian science are based in Singapore, Taipei or Hong Kong; a second group, especially in agronomy and biomedicine, is produced in India and in Pakistan.

Similar considerations apply to the various organisations that have sought to rally national scientific academies across the continent. The Federation of Asian Scientific Academies and Societies, founded with Indian government support in Delhi in 1984 before the Federation's shift to Malaysia in 2000, recruited academies from southern and southeastern Asian states alongside Australia and New Zealand. No Middle Eastern state took part. A later grouping with some important overlapping membership, the Association of Science Academies in Asia, was founded in Soeul in 2000. It was notable for the absence 
of Australasian academies and the presence of the Russian Federation, of some newly independent central Asian republics (Georgia, Kazakhstan, Tajikstan, Uzbekistan), as well as the participation of several Middle Eastern states (Iran, Israel, and associations with Jordan and Saudi Arabia). With the aid of the InterAcademy partnership, an Italian-funded agency based in Trieste, the two Asian organisations merged in 2012. The Trieste partnership itself imposes a subtly different institutional geography, distinguishing Asian academies into three groups: Middle East and Central Asia, South Asia, South East Asia and the Pacific. Russia is assigned to a Central and Eastern European zone. In 2014, also under Korean sponsorship, the Council of Asian Science Editors was formed with the aims of registering the increased output of science papers within Asia, and insistence on the contrast with the geographical sites of the journals where they are principally published, especially under intensified international corporate oligopoly in science publication. In these initiatives and debates, there is little doubt that the definitions of Asia's scope and significance play a vital role in the current politics of knowledge. ${ }^{5}$

Part of this significance, no doubt, is the intriguing relation between Asia understood as a geographical region where specific forms of knowledge have been cultivated, and Asia understood as itself the topic of scientific definition and inquiry. The Enlightenment notion of 'Asiatick learning' was deliberately ambiguous, referring both to knowledge of Asia and also knowledge produced within Asia so defined. William Jones' celebrated fantasy of Asian geography and the apparently all-seeing gaze of European sciences was artfully located on board the frigate HMS Crocodile in August 1783 on its voyage across the Indian ocean from the Comoros Islands to the Hooghly, during which 'India lay before us, and Persia on our left, whilst a breeze from Arabia nearly blew on our stern'. Jones evoked 'so noble an amphitheatre, almost encircled by the vast regions of Asia, which has ever been esteemed the nurse of the sciences'. Presented in a lecture in Calcutta the following May, this reverie moved at once between the geographical and historical conditions of Asian sciences and the necessity of studying them scientifically, insisting specifically on an establishment of an academy and a definition of boundaries. 'Considering Hindustan as a centre', the 
academy's field would be informed by scriptural histories common amongst learned Jesuit oriental scholarship as well as enlightened philology. It must incorporate Japan and China, Tartary and Tibet, Persia and Arabia, and indeed Egypt: 'you may not be displeased occasionally to follow the streams of Asiatick learning beyond its natural boundary'. Jones explicitly barred the term 'oriental', since merely relative to Europe's position. Instead, the key phrase 'natural boundary' played a decisive role in scientific organisation and the geography of knowledge. 6

As has often been clear in the history of the sciences, alien as well as indigenous judgments of the condition of Asian cultures have been linked with judgments of the state of those cultures' apparent scientific achievements, while scientific study has been intensively devoted to the definition of Asian geographical situation and variation in the explication of its cultural development. ${ }^{7}$ The point has been well made by the eminent Beijing intellectual historian Wang Hui, whose arguments for the heterogeneous and irrevocably political importance of projects that seek to define a unitary or panAsian culture are welcomed by Subrahmanyam. Wang Hui has consistently stressed the European origins of 'the idea of Asia', and described how 'a new world map' was constructed within the European sciences in the epoch of William Jones and Adam Smith. This map made Asia an indispensable component of narratives and charts of emergent modernity. On this showing, the project is to trace how such scientifically generated world maps were used by imperial and anticolonial movements alike, not to commit the error of supposing that externally produced maps must therefore have no significance nor grip within the range of Asian cultures: 'The criticism of Euro-centrism should not seek to confirm Asiacentrism'. 8

Subrahmanyam's argument about connexions, strong and weak, happily avoids this mistake. His wide-ranging surveys extend from sixteenth century Timurid military campaigns in Kashgar and Tibet to the geopolitical visions of a Meiji era art historian. They urge a convincingly multifarious and heterogeneous account of Asian worlds. An intriguing juxtaposition is suggested between the 
notion of Asia as an externally developed European tool of distinction and the uneven emergence of a sense of Asia amongst its own inhabitants. It is presumably of significance that Subrahmanyam finds this sense already tentatively emergent in the decades around 1700. It is seemingly evident, he argues, in the first printed Ottoman cartographies, published during the Tulip Epoch, a conjuncture crucial in historical debates on Istanbul's cultural and diplomatic relations with western and central Europe and crucial, too, in the production there of versions of significant early modern European astronomical, natural philosophical and cosmological texts. To his 1732 edition of Çelebi's Cihānnümā, discussed here by Subrahmanyam, the printer and diplomat Ibrahim Müteferrika added a fascinating essay on the history of astronomy, presenting the principles of heliocentrism. He expanded on this the following year in his Turkish version of the canonical work of Baroque comparative cosmology and its iconography, Andreas Cellarius' Harmonia macrocosmica. Further works followed, including treatises on navigational science, on magnetism and on geography. ${ }^{9}$

Subrahmanyam is therefore right to stress the crucial role of the history of mapping and of the visual techniques of geography and cosmology in models and counter-models of unified or heterogeneously networked Asian spaces. Astronomical sciences and the visual technologies they cultivated in charts and diagrams became a way of judging other societies and a means to find out more about what those societies knew. In his praise of Jones' Asiatic Society and the recovery of 'the astronomy of the Brahmins', the Edinburgh mathematics professor John Playfair explained that astronomy was no specialist science but a means of unlocking humanity's past. 'It is through the medium of astronomy alone that a few rays from those distant objects can be conveyed in safety to the eye of a modern observer free from the false colourings of vanity and superstition'. ${ }^{10}$ One striking feature of such claims is the importance they would grant to discourses on the emergence of Asian knowledges. Just as visions of a unified Asia discharged potent political energies, so notions of a singular system of science that specified Asian histories and historical geographies were tools of important ideological conflict. 
A familiar example of this relation between sophisticated astronomical and geographical knowledges and the specification of Asia's unitary origins and scientific importance is provided by the programme of Playfair's principal source, the eminent French astronomer and academician Jean-Sylvain Bailly. Bailly was an expert protagonist of precision astronomical analysis at the Parisian centre of academic culture, ally of Buffon and of Benjamin Franklin, manager of an astronomical observatory at the Louvre. In the 1770s he launched a vast project to write the history of ancient astronomy, using the level of astronomical prowess as a means of calibrating the social and cultural development of ancient peoples. The project's most significant aim was to produce a general developmental history of Asia, including works on the origin of Asian sciences in 1777 and on the primeval history of Asia in 1779 . His sources evidently included materials gathered by Jesuit missionaries in south Asia such as Guy Tachard and Gaston-Laurent Coeurdoux, who had accumulated invaluable analysis of Sanskrit astronomical texts and, in the case of Coeurdoux, who offered speculative if compelling genealogies of the geographical and erudite sources of Asian learning. Important prompts for the project also included Anquetil-Duperron's 1771 version of the Zend-Avesta and Court de Gébelin's remarkable treatise on the world before the Deluge, Le monde primitif (1773). ${ }^{11}$

An impressive catalogue of common astronomical and cultural features, including measures of weeks and years, the division of the zodiac, the precession of the position of the fixed stars, and, in particular, the establishment of a founding astronomical epoch of around 3100 BCE, identical to the Sanskritic astronomical epoch of the Kali Yuga, all told as signs of a shared astral culture spread through Asia, from Mesopotamia to China. In common with some of his learned colleagues, Bailly argued that an original and sophisticated astronomical system had been lost, only to be preserved in northern Tartary and Scythia above the fiftieth parallel. He rejected Voltaire's notorious claims for the immemorial antiquity and virtue of the 'Brahmanes', countering that instead it was from far northern Asia that this learning then spread south across the great 
mountain ranges into central and southern lands. Asian unity and diversity were thus simultaneously given appropriate genealogies. Sophisticated precision astronomy could hence establish its command over Asian geography and history; and in the same project, this science found its origins there as an Asian science. 'I have pleaded the cause of Asia and the ancient inhabitants of the Earth', he declared. ${ }^{12}$

The polemic between Bailly and Voltaire that flourished in the mid-1770s throws some helpful light on the comparative and political assumptions that undergirded the formation of different views of Asian commonalty in sciences and in geography, characteristic of the discourse on Asiatic sciences and on the scientific specification of Asia that Wang Hui identifies with this enlightened conjuncture. Philology, climatology and astronomy were then supposed to work together to help forge narratives of original truth, its loss and its imperfect and uneven current distribution. Voltaire held it barely credible that Bailly's Scythians, human 'tigers' who'd laid waste to the Gangetic plain, would 'stock their lairs with quadrants and astrolabes'. Bailly, keen reader of François Bernier's reports from the Mughal court, countered that were some 'Hindu Bernier' to attend orthodox Catholic lectures in Paris or Rome, 'would he not take us all for fools and imbeciles?'13

It was therefore quite wrong to derive genealogical arguments solely from current systems of orthodoxy and established institutions. Bailly made a telling comparison, peculiarly pointed at the moment of the American creoles' Declaration of Independence, with the future development of the Americas. There, so the astronomer argued, 'the colonies will separate and produce new peoples and independent states. Yet some of our own institutions will survive; knowledge of physics and astronomy will be preserved'. For 'those who will weigh them in the philosophical balance', it would then seem extraordinary that such advanced knowledges could exist in such newborn nations. Diffusionism of just the form that Bailly urged in the Asian case would be the sole explanation. But there was an important contrast too. Whereas in the American case it would be the surprising sophistication of trans-Atlantic youthfulness that demanded a 
diffusionist origin, in the Asian case it was its inverse, shared astral sciences once distributed across the continent now decadent and slothful. ${ }^{14}$

What was perhaps most at stake in such visionary fantasies of Asian astronomy and Asian unity was a set of arguments about what features might connect and separate cultures. In the stories developed by eighteenth-century missionaries and astronomers, philosophers and critics, it was crucial to understand the geopolitcs of long-range networks and their origins. Bailly was by no means alone in sternly contrasting European globalism with Asian parochialism. 'It seems obvious to me', he wrote in 1777, that 'the Asian nations are still isolated. Concentrated within their frontiers, like the inhabitants of a town within their walls, they have only made war through sorties and excursions, and commerce solely with their neighbours and with little energy'. Subrahmanyam's lecture shows dramatically how absurd were these views, yet it also makes a great deal of the comparative limitation of the world-knowledge of the great early modern regimes. The Mughals apparently lost links and interests in central Asia even as the networks with Iran considerably strengthened. Ottoman connexions with China also seem to reveal similarly uneven forms of limitation. In his own analyses of the pathways between these regions as he understood them in the later eighteenth century, Bailly sought to make sense of how such networks could be so patchy and so important. In an astonishingly fanciful essay that found Atlantis in northern Asia, he reflected on the strange role played by the great mountain ranges of central Asia. Disciple and collaborator of Buffon, Bailly was especially fascinated by the climate and mountain geography of central and northern Asia. It was in the furthest north that had lived learned peoples once possessed of the same knowledges cultivated in Bailly's Paris. 'In the interior civilisation was established and enlightenment born, and these barriers raised against the North were the demarcation line'. Yet at the same time these mountains, and the wider physical and cultural geography of central Asia, needed essentially to be understood as a shared system that showed what bound the world together. 'The Indians, the Chinese, the Persians, left from the fortification line we have traced across Asia...At the same time as this chain is a barrier, it is still a common origin'. ${ }^{15}$ 
The logic might now seem understandably 'ludicrous', as Hong Kong journalists put it. Yet Bailly's programme would soon become a major resource for William Jones and his collaborators' work in 'Asiatick sciences', and would long provide resources, too, for scholars keen to demonstrate the antiquity and significance of Asian astronomies. ${ }^{16}$ Compare Okakura Tenshin's 1904 evocation of 'snowy barriers' that link what he called Asian 'thought-inheritance', and his equally stereotypical reference to 'the great moving sea of the Tartar hordes whose waves recoiled from the long walls of the North'. Subrahmanyam closes his lecture by indicating how Okakura's views of 'origins and barriers' undergird complex and polemically political maps of Asian unity and diversity. The interest is thus not to ignore nor dismiss such projects, but rather to understand where they came from and where they might travel.

${ }^{1}$ Friedrich Nietzsche, Untimely Meditations, ed. Daniel Breazeale (Cambridge: Cambridge University Press, 1997), 67.

2 James Clifford, The Predicament of Culture: Twentieth-century Ethnography, Literature and Art (Cambridge, MA. : Harvard University Press, 1988), 260-2; Peter van der Veer, "The Foreign Hand: orientalist discourse in sociology and communalism', in Carol Breckenridge and Peter van der Veer (eds.), Orientalism and the Postcolonial Predicament (Philadelphia: University of Pennsylvania Press, 1993), 24-44, on 25-28.

${ }^{3}$ Far Eastern Economic Review (12 February 1987): Philip Bowring, 'What is Asia?', 30-31; Jagdish Bhatia, 'Self-enclosed village India', 33-35; Anwar Nasr, 'Middle East countries struggle to be recognised', 42-43.

4 Bowring, 'What is Asia?', 31.

5 For scientometrics of Asian publications see S. Arunachalam and K.C.Garg, 'Science on the periphery', Journal of Information Science, 12 (1986), 105-17; S.Arunachalam, R.Srinivasan and V.Raman, 'International collaboration in science', Scientometrics 30 (1994), 7-22; Tuan V. Nguyen and Ly T. Phan, 'Scientific output and its relation to the knowledge economy', Scientometrics 89 (2011), 107-17. 
${ }^{6}$ William Jones, 'A discourse on the institution of a society' (May 1786), in Works, 6 vols. (London: Robinson and Evans, 1799), 1:1-8, on 1-4. For scriptural scholarship and enlightened learning see Alun David, 'Sir William Jones, Biblical orientalism and Indian scholarship', Modern Asian Studies 30 (1996), 173-84; Ines Županov and Marie Fourcade, 'La question des Lumières en Inde', in Županov and Fourcade (eds.), L'Inde des Lumières: discours, histoire, savoirs (Paris: Éditions de l'École des Hautes Études en Sciences Sociales, 2013), 13-49.

${ }^{7}$ Michael Adas, Machines as the measure of men: science, technology and ideologies of western dominance (Ithaca: Cornell University Press, 1989); Mohamad Tavakoli-Targi, Refashioning Iran: Occidentalism, orientalism and Historiography (New York, Palgrave, 2001); Kapil Raj, Relocating Modern Science: Circulation and the Construction of Knowledge in South Asia and Europe 16501900 (New York: Palgrave Macmillan, 2007).

8 Wang Hui, 'Reclaiming Asia from the West: Rethinking Global History', AsiaPacific Journal: Japan Focus (2004), www.japanfocus.org/-WangHui/1781/article.html, accessed 20 April 2015.

${ }^{9}$ Can Erimtan, Ottomans Looking West: the Origins of the Tulip Age and its Development in Modern Turkey (London: I.B.Tauris, 2008); Ekmeledin Ihsanoglu, 'The introduction of western science to the Ottoman world: a case study of modern astronomy 1660-1860' in Ihsanoglu, Science, technology and learning in the Ottoman Empire (Aldershot: Ashgate, 2004), 1-44, on 15-20; Vefa Erginbas, Enlightenment in the Ottoman Context: Ibrahim Müteferrika and his Intellectual Landscape (Leiden: Brill, 2013).

10 John Playfair, 'Remarks on the Astronomy of the Brahmins', 2 (1790), 135-92, on 189.

11 Edwin Burrows Smith, 'Jean-Sylvain Bailly: astronomer, mystic, revolutionary', Transactions of the American Philosophical Society 44 (1954), 427-538, on 455-9; Sylvia Murr, L'Inde philosophique entre Bossuet et Voltaire, 2 vols. (Paris: Adrien Maisonneuve, 1987), 2:177; Dhruv Raina, 'Betwixt Jesuit and Enlightenment historiography: Jean-Sylvain's History of Indian Astronomy', Revue d'histoire des mathématiques 9 (2003), 253-306, on 261-7.

12 Jean-Sylvain Bailly, Essai sur les fables et sur leur histoire (Paris: Guillaume de Bure, 1797), 4; Smith, 'Bailly', 480-1. 
${ }^{13}$ Smith, 'Bailly', 460, 461 n.66; Raina, 'Betwixt Jesuit and Enlightenment historiography', 270-8.

${ }^{14}$ Jean-Sylvain Bailly, Lettre sur l'origine des sciences et sur celles des peuples de l'Asie (Paris: Debure, 1777), 198; Smith, 'Bailly', 462 n. 85.

15 Jean-Sylvain Bailly, Lettres sur l'Atlantide de Platon et l'ancienne Histoire de l'Asie (Paris: Debure, 1779), 203-4, 208.

16 Raina, 'Betwixt Jesuit and Enlightenment historiography', 299; Županov and Fourcade, 'La question des Lumières'. 